\title{
Perineural Spread of Malignant Melanoma of the Head and Neck: Clinical and Imaging Features
}

\author{
Patrick C. Chang, Nancy J. Fischbein, Timothy H. McCalmont, Mohammed Kashani-Sabet, \\ Elizabeth M. Zettersten, Amon Y. Liu, and Jane L. Weissman
}

\begin{abstract}
BACKGROUND AND PURPOSE: Extension of malignant melanoma along cranial nerves is a little-known complication of malignant melanoma of the head and neck. We describe the clinical and MR imaging findings of perineural spread of malignant melanoma to cranial nerves, emphasizing that this entity occurs more commonly with desmoplastic histology and may have a long latent period following primary diagnosis.

METHODS: At two institutions, we identified and retrospectively reviewed eight cases of malignant melanoma of the head and neck that had MR imaging evidence of perineural spread of disease. All patients underwent confirmatory tissue sampling.

RESULTS: Seven patients had melanomas of the facial skin or lip, and one patient had a primary sinonasal lesion. By histopathology, these melanomas included five desmoplastic, two mucosal, and one poorly differentiated melanotic spindle-cell tumor. All patients developed symptomatic cranial neuropathy an average of 4.9 years from the time of initial diagnosis. MR imaging demonstrated postgadolinium enhancement of at least one branch of the trigeminal nerve in all cases and of at least one other cranial nerve in five cases. Other findings included abnormal contrast enhancement and soft tissue thickening in the cavernous sinus, Meckel's cave, and/or the cisternal segment of the trigeminal nerve.

CONCLUSION: Although perineural spread of disease occurs most commonly with squamous cell carcinoma and adenoid cystic carcinoma, malignant melanoma must also be included in this differential diagnosis, particularly if the patient's pathology is known to be desmoplastic. Similarly, any patient with malignant melanoma of the head and neck who undergoes MR imaging should receive an imaging assessment focused on the likely routes of perineural spread.
\end{abstract}

The incidence of malignant melanoma is increasing at a faster rate than any other human cancer, and the increase in mortality rate is second only to lung cancer (1). Approximately 53,000 new cases and more than 7000 melanoma deaths were predicted for the year 2002 (2). Melanoma accounts for $5 \%$ of all skin cancer but causes $65 \%$ of skin cancer deaths (3). Overall, $20 \%$ of melanomas occur in the head and neck (4).

Received March 13, 2003; accepted after revision May 20, 2003.

From the Departments of Radiology (P.C.C., N.J.F.), Dermatopathology (T.H.M.), and Dermatology (M.K.-S., E.M.Z.), University of California, San Francisco, School of Medicine, San Francisco, CA; Department of Radiology (A.Y.L.), Medical College of Virginia, Richmond, VA; and the Departments of Radiology and Otolaryngology (J.L.W.), Oregon Health Sciences University, Portland, OR.

Address correspondence to Nancy J. Fischbein, MD, Department of Radiology, University of California, San Francisco, School of Medicine, Box 0682, 505 Parnassus Avenue, San Francisco, CA 94143.

(C) American Society of Neuroradiology
Perineural spread of tumor is a well-described complication of squamous cell carcinoma, adenoid cystic carcinoma, and lymphoma (5) of the head and neck. Perineural spread of tumor most commonly occurs along the facial nerve and branches of the trigeminal nerve (6), but other cranial nerves can also be involved. Some patients may be clinically asymptomatic even when they have gross spread of disease by imaging or histopathology, whereas others may initially be misdiagnosed with "benign" conditions such as trigeminal neuralgia or Bell palsy (7). Recognition of perineural spread of tumor at MR imaging usually changes treatment goals from cure to palliation and can therefore significantly affect patient care.

Perineural spread of malignant melanoma of the head and neck has been reported $(8,9)$ but is considered rare. Our purpose is to present eight patients with perineural spread of head and neck melanoma and discuss the pertinent clinical and diagnostic imaging features. 
TABLE 1: Clinical characteristics of patients with perineural spread of malignant melanoma

\begin{tabular}{|c|c|c|c|c|c|c|c|c|c|c|}
\hline $\begin{array}{l}\text { Patient } \\
\text { no. }\end{array}$ & $\begin{array}{l}\text { Age } \\
\text { (years)/ } \\
\text { Sex }\end{array}$ & Risk Factors & $\begin{array}{c}\text { Original Presenting } \\
\text { Lesion }\end{array}$ & $\begin{array}{c}\text { Time to } \\
\text { Develop } \\
\text { Clinical } \\
\text { Neuropathy }\end{array}$ & Pathology & $\begin{array}{c}\text { Delay in } \\
\text { Diagnosis of } \\
\text { Perineural } \\
\text { Disease }\end{array}$ & $\begin{array}{c}\text { Cranial } \\
\text { Neuropathies }\end{array}$ & Biopsy & $\begin{array}{c}\text { Years of } \\
\text { Follow-Up }\end{array}$ & Outcome \\
\hline 1 & $59 / \mathrm{M}$ & $\begin{array}{l}\text { Lentigo } \\
\text { maligna }\end{array}$ & Mass on lower lip & 11 years & Mucosal & 13 months & V2, V3, VII & Mandibular nerve & 4 & AWD \\
\hline 2 & $29 / \mathrm{M}$ & None known & Mass on lower lip & 3 years & Desmoplastic & 1 month & V3 & $\begin{array}{l}\text { Inferior alveolar } \\
\text { nerve }\end{array}$ & 5 & AWD \\
\hline 3 & $78 / \mathrm{M}$ & $\begin{array}{l}\text { Lentigo } \\
\text { maligna }\end{array}$ & $\begin{array}{l}\text { Pigmented lesion } \\
\text { over left } \\
\text { forehead }\end{array}$ & 1.5 years & Desmoplastic & 10 months & $\begin{array}{l}\text { III, IV, V1, } \\
\text { VI, VII }\end{array}$ & $\begin{array}{l}\text { Supraorbital nerve, } \\
\text { CT-FNA }\end{array}$ & 2 & DOD \\
\hline 4 & $41 / \mathrm{F}$ & None & $\begin{array}{l}\text { Right } \\
\text { nasopharyngeal } \\
\text { mass }\end{array}$ & 3 years & Mucosal & N/A & $\begin{array}{l}\text { V1, V2, VI, } \\
\text { VII }\end{array}$ & Infraorbital nerve & 1 month & Unknown \\
\hline 5 & $70 / \mathrm{F}$ & $\begin{array}{l}\text { Family } \\
\text { history of } \\
\text { melanoma }\end{array}$ & $\begin{array}{l}\text { Mass over right } \\
\text { nose }\end{array}$ & 2.5 years & Desmoplastic & 6 months & $\begin{array}{l}\text { III, IV, V, VI, } \\
\text { VII, VIII, } \\
\text { IX, X, XI, } \\
\text { XII }\end{array}$ & $\begin{array}{l}\text { Infraorbital nerve, } \\
\text { CT-FNA }\end{array}$ & 5 & DOD \\
\hline 6 & $49 / \mathrm{F}$ & None & Mass on upper lip & 3 years & Desmoplastic & 1 month & $\mathrm{V} 2$ & Infraorbital nerve & 1 & AWD \\
\hline 7 & $70 / \mathrm{F}$ & $\begin{array}{l}\text { Lentigo } \\
\text { maligna }\end{array}$ & $\begin{array}{l}\text { Left supraorbital } \\
\text { skin mass }\end{array}$ & 12 years & Spindle-cell & 11 months & III, V1, VI & Supraorbital nerve & 2 & DOD \\
\hline 8 & $64 / \mathrm{M}$ & None & $\begin{array}{l}\text { Left infraorbital } \\
\text { skin mass }\end{array}$ & 3 years & Desmoplastic & 8 months & $\mathrm{V} 1, \mathrm{~V} 2$ & Infraorbital nerve & 2 & DOD \\
\hline
\end{tabular}

Note.-AWD, alive with disease; DOD, dead of disease; N/A, not applicable.

\section{Methods}

A total of eight patients with evidence for perineural spread of malignant melanoma of the head and neck were retrospectively identified, with six patients identified over the course of 8 years (1994-2002) at one institution and two patients over 3 years (1994-1996) at a second institution. These individuals had primary malignant melanoma of the head and neck arising from a cutaneous or mucosal surface confirmed by pathology. No patients had a melanoma elsewhere on the body. Patients ranged in age from 29 to 78 years, with a mean age of 58 , and included five males and three females. We obtained institutional review board approval to perform this study.

All patients were examined with MR imaging of the skull base and extracranial head and neck following onset of symptomatic cranial neuropathy. Imaging included sagittal, axial, and coronal T1-weighted images, axial fast spin-echo T2weighted images with fat saturation, and axial and coronal T1-weighted images postgadolinium with fat saturation. Images were assessed qualitatively for evidence of perineural spread of tumor on the basis of criteria described by multiple authors (6, $8,10)$. In brief, these features included abnormal nerve thickening and/or contrast enhancement, expansion and/or erosion of skull base foramina, enhancing mass in Meckel's cave, lateral bulging of the cavernous sinus dura, and denervation atrophy of the muscles of mastication.

Perineural spread or extension of tumor identified by imaging implies direct extension of tumor along the perineural tissue planes that follow the course of a named nerve (typically a cranial nerve in the head and neck). Perineural invasion is a pathologic diagnosis and implies demonstration of tumor extension into neural structures, which may be large cranial nerves or small unnamed nerves in the vicinity of the tumor (11). All patients underwent direct tissue sampling by open biopsy to confirm perineural extension of the original tumor. Biopsy specimens were analyzed by pathology by using light microscopy and immunohistochemistry. Patient characteristics are summarized in Table 1.

\section{Results}

All of our patients had a history of a melanotic lesion of the head and neck that was treated by local excision. Four patients had a predisposing risk factor for malignant melanoma, including lentigo maligna in patients 1,3 , and 7 and a family history of malignant melanoma in patient 5 .

In all cases, the patient's melanoma was complicated by symptomatic cranial neuropathy (Table 1). Patients presented with cranial neuropathy an average of 4.9 years (range, 1.5-12 years) after the initial lesion was diagnosed. Cranial nerve $(\mathrm{CN}) \mathrm{V}$ was affected in all patients and CN VII in four patients (1, 3,4 , and 5). Clinical neuropathies of CNs III, IV, and VI were noted in two patients (3 and 5), and one of these patients (5) with extensive metastatic disease additionally developed dysfunction of CNs VIII, IX, $\mathrm{X}, \mathrm{XI}$, and XII.

Gross perineural spread of tumor was observed on MR imaging in all cases (Table 2). All patients exhibited abnormal enlargement and/or enhancement of involved cranial nerves on postcontrast T1-weighted spin-echo images with fat suppression (Fig 1). Denervation atrophy of the muscles of mastication was seen in five patients (Fig 2). There was also enhancement of the gasserian ganglion in Meckel's cave and of the ipsilateral cavernous sinus in six of eight patients. Two patients demonstrated intraaxial extension of perineural disease: patient 5 demonstrated involvement of the pons, and patient 7 had enhancement of the pons and cerebellar peduncle (Fig 3). Imaging findings are summarized in Table 2.

Following MR imaging, perineural spread of disease was confirmed by open biopsy in all cases. Required approaches included craniotomy, submandibular trian- 
TABLE 2: MR imaging findings in perineural spread of malignant melanoma

\begin{tabular}{|c|c|c|c|c|c|c|}
\hline $\begin{array}{l}\text { Patient } \\
\text { No. }\end{array}$ & Abnormal Cranial Nerves & $\begin{array}{c}\text { Nerve } \\
\text { Enlargement }\end{array}$ & $\begin{array}{c}\text { Nerve } \\
\text { Enhancement }\end{array}$ & $\begin{array}{c}\text { CS } \\
\text { Mass }\end{array}$ & $\begin{array}{l}\text { MC } \\
\text { Mass }\end{array}$ & $\begin{array}{l}\text { Denervation } \\
\text { Change in } \\
\text { Muscles of } \\
\text { Mastication }\end{array}$ \\
\hline 1 & V2, V3, VII & $\mathrm{Y}$ & $\mathrm{Y}$ & $\mathrm{Y}$ & $\mathrm{Y}$ & $\mathrm{Y}$ \\
\hline 2 & V3 & $\mathrm{Y}$ & $\mathrm{Y}$ & $\mathrm{N}$ & $\mathrm{Y}$ & $\mathrm{Y}$ \\
\hline 3 & III, IV, V1, V3, VI, VII & $\mathrm{Y}$ & Y & Y & Y & $\mathrm{Y}$ \\
\hline 4 & V1, V2, VI, VII & $\mathrm{Y}$ & $\mathrm{Y}$ & $\mathrm{Y}$ & $\mathrm{Y}$ & $\mathrm{N}$ \\
\hline 5 & $\begin{array}{l}\text { III, IV, V3, VI, VII, VIII, } \\
\text { IX, X, XI, XII }\end{array}$ & $\mathrm{Y}$ & $\mathrm{Y}$ & $\mathrm{Y}$ & $\mathrm{Y}$ & $\mathrm{Y}$ \\
\hline 6 & $\mathrm{~V} 2$ & $\mathrm{Y}$ & Y & $\mathrm{N}$ & $\mathrm{N}$ & $\mathrm{N}$ \\
\hline 7 & III, V1, V3, VI & $\mathrm{Y}$ & $\mathrm{Y}$ & $\mathrm{Y}$ & $\mathrm{Y}$ & $\mathrm{Y}$ \\
\hline 8 & $\mathrm{~V} 1, \mathrm{~V} 2$ & $\mathrm{Y}$ & $\mathrm{Y}$ & Y & Y & $\mathrm{N}$ \\
\hline
\end{tabular}

Note.-CS, cavernous sinus; MC, Meckel's cave; N, no; Y, yes.
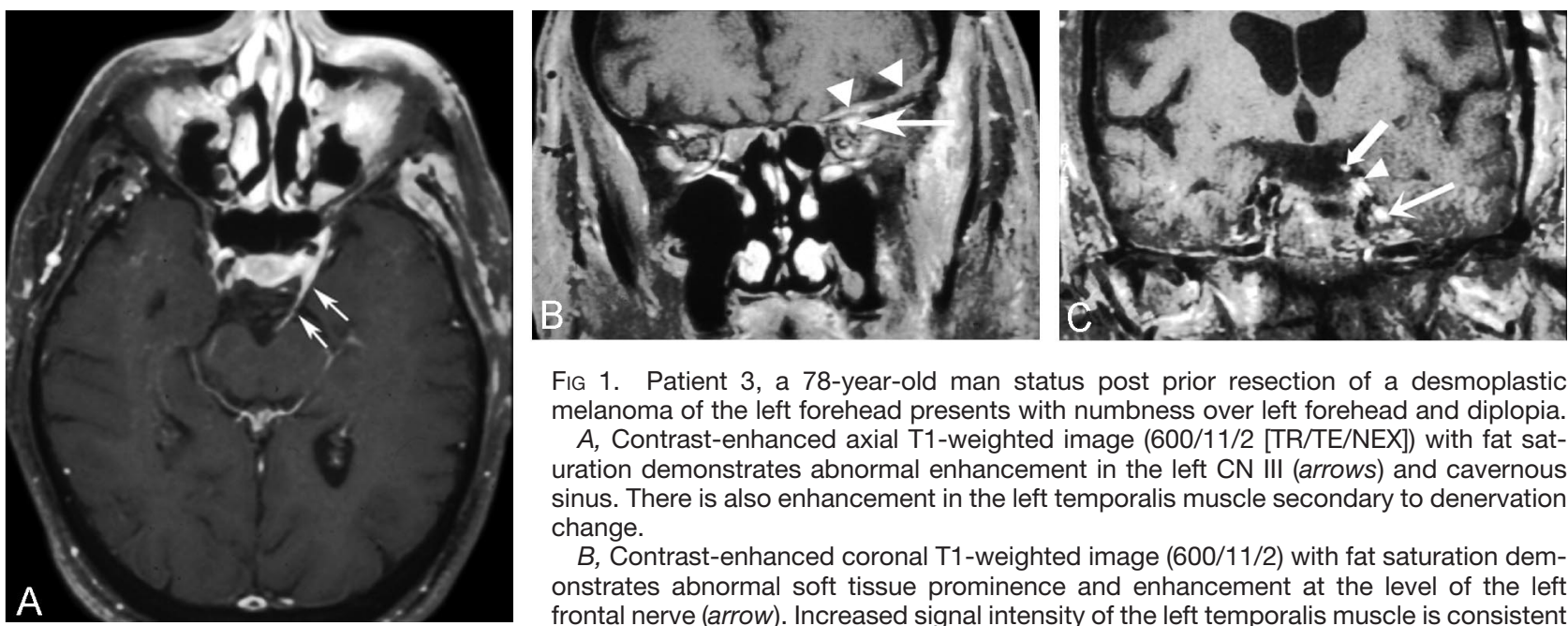

FIG 1. Patient 3, a 78-year-old man status post prior resection of a desmoplastic melanoma of the left forehead presents with numbness over left forehead and diplopia.

$A$, Contrast-enhanced axial T1-weighted image (600/11/2 [TR/TE/NEX]) with fat saturation demonstrates abnormal enhancement in the left CN III (arrows) and cavernous sinus. There is also enhancement in the left temporalis muscle secondary to denervation change.

$B$, Contrast-enhanced coronal T1-weighted image (600/11/2) with fat saturation demonstrates abnormal soft tissue prominence and enhancement at the level of the left frontal nerve (arrow). Increased signal intensity of the left temporalis muscle is consistent with denervation change. In addition, a small left subdural hematoma (arrowheads) is incidentally noted in this elderly patient. This demonstrated intrinsic T1 shortening consistent with blood products and resolved on a follow-up scan (not shown).

$C$, A more posterior contrast-enhanced coronal T1-weighted image (600/11/2) with fat saturation demonstrates enhancing soft tissue in Meckel's cave on the left (lower arrow), consistent with involvement of the gasserian ganglion, as well as abnormal enhancement and enlargement of the left CN III (upper arrow) and abnormal enhancement and enlargement of the left CN VI (arrowhead) as well.

gle dissection, maxillectomy, and/or ethmoidectomy. For patients with available clinical data, the average delay in diagnosis from onset of cranial neuropathy until a positive biopsy for perineural spread was obtained was 7.1 months (range, 1-13 months). CT-guided fine needle aspiration of soft tissue at the level of foramen ovale had been performed in two patients but was nondiagnostic, and open biopsies were ultimately performed. Five patients had biopsies revealing desmoplastic malignant melanoma (patients 2, 3, 5, 6, and 8). Two patients had mucosal melanoma $(1,4)$, and one patient (7) had a poorly differentiated spindle-cell melanotic tumor.

Each patient had been treated by local excision with curative intent at the time of initial presentation. Once patients developed symptoms of cranial neuropathy or demonstrated evidence of perineural spread by MR imaging, they were treated with a palliative approach to reduce tumor burden conservatively through radiation and chemotherapy rather than more radical surgical techniques. Five patients received conventional external beam radiation therapy $(2,3,4,6$, and 8$)$, four received gamma-knife radiosurgery $(2,4,5$, and 7$)$, and two (2 and 4) received chemotherapy. All patients were followed with serial MR imaging to monitor their response to therapy.

Patients had an average of 3 years of follow-up after their presentation with cranial neuropathy, with a range of 1 month to 5 years. Patients $3,5,7$, and 8 died because of progression of disease, whereas patients 1,2 , and 6 are alive with disease. Patient 4 was lost to follow-up. Of the four patients treated with gamma knife radiosurgery, follow-up scans are available on only two (patient 2 and 5). Gamma knife radiosurgery improved symptoms for 1 year in patient 5 and for 9 months in patient 2, but both of these patients then developed progressive disease.

\section{Discussion}

Perineural spread of head and neck cancer is a well-described complication of squamous cell carcinoma, adenoid cystic carcinoma, and lymphoma $(5,6$, $10)$, but other tumors of the head and neck, such as malignant melanoma, can also spread in this manner 
FIG 2. Patient 2, a 29-year-old man status post prior resection of a desmoplastic melanoma of the lower lip presents with decreased sensation over his left lower jaw.

$A$, Contrast-enhanced axial T1weighted image (600/11/2) with fat saturation demonstrates a mass (arrows) just medial to the mandibular foramen, as well as subtle decrease in bulk of the left-sided muscles of mastication.

$B$, Contrast-enhanced coronal T1weighted image (600/11/2) with fat saturation demonstrates enlargement and abnormal enhancement of the left $\mathrm{CN}$ V3 (arrowheads) from the level of the mandibular foramen up to the left Meckel's cave, consistent with perineural spread of tumor.

FIG 3. Patient 7, a 70-year-old woman status post prior resection of a left supraorbital lesion presents with a palsy of her left CN V1.

$A$, Contrast-enhanced axial T1weighted MR image (600/11/2) with fat saturation demonstrates subtly asymmetrical enhancing soft tissue (anterior arrow) in the left superior orbital fissure/ cavernous sinus, as well as the anterosuperior aspect of Meckel's cave (posterior arrow).

$B$, Six months later, repeat contrast-
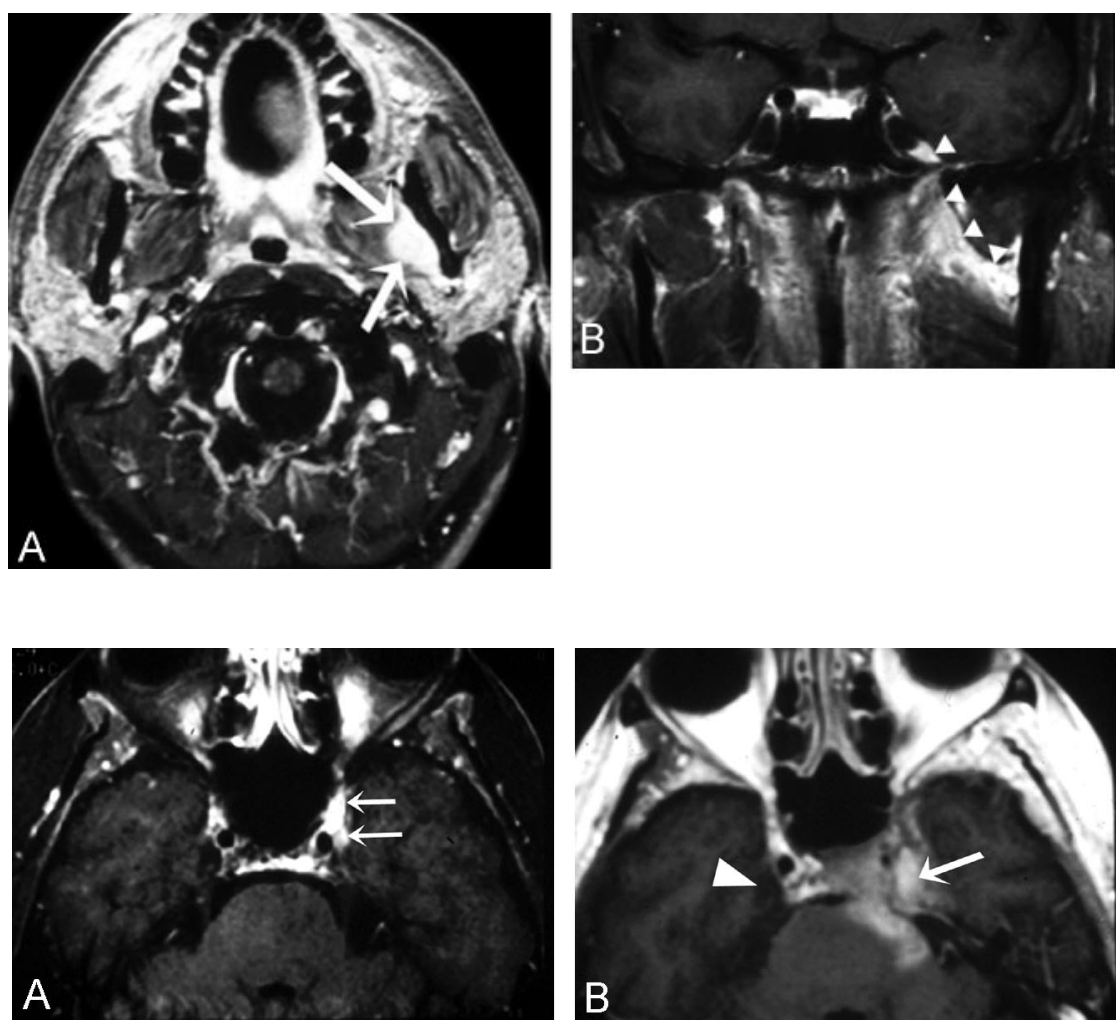

enhanced axial T1-weighted image (600/11/2) demonstrates interval disease progression along the cisternal segment of the trigeminal nerve to involve the pons and cerebellar peduncle. Enhancing soft tissue completely fills Meckel's cave on the left (arrow) as compared with the normal right side (arrowhead).

and may lead to symptomatic cranial neuropathy. Of the different subtypes of melanoma, the desmoplastic variant has been noted to have a clear predilection for neurotropism (12). We describe MR imaging features of eight patients with malignant melanoma to emphasize that patients who develop cranial neuropathy and have a history of head and neck melanoma should be carefully evaluated for perineural spread of tumor because this alters both treatment and prognosis.

Imaging of perineural spread of melanoma is best accomplished with MR, in light of its superior soft tissue contrast and multiplanar capability. Contrastenhanced T1-weighted spin-echo images with fat-suppression are often most helpful for diagnosis (8). As with other tumors that demonstrate perineural spread, principle MR features include abnormal nerve thickening with enhancement after contrast, concentric expansion and/or erosion of skull base foramina and extracranial bony nerve canals, enhancing mass in Meckel's cave, lateral bulging of the cavernous sinus dura, and denervation atrophy of innervated muscles such as the masticator muscles. Tumor extension through the foramen ovale and perineural spread into Meckel's cave is best seen on coronal T1-weighted images postgadolinium with fat saturation (10), whereas axial noncontrast T1-weighted images without fat saturation are very useful for evaluation of the pterygopalatine fossa and other fatty spaces adjacent to the skull base, as well as for assessment of skull base marrow infiltration.

Perineural spread of tumor most commonly in- volves the branches of $\mathrm{CN} \mathrm{V} \mathrm{(10).} \mathrm{The} \mathrm{mandibular}$ nerve can be a route of tumor spread to the cavernous sinus for tumors of the nasopharynx, masticator space, and parapharyngeal space, as well as lesions of the lower lip and chin. The maxillary nerve can transmit tumor from the palate, maxilla, nose and nasopharynx, as well as overlying cutaneous surfaces. Tumor over the eye, forehead, or frontal sinus can spread along the ophthalmic division of CN V. Depending on the site of origin, the facial nerve may also be primarily involved or may be involved via spread from $\mathrm{CN} \mathrm{V}$ along the greater superficial petrosal nerve (GSPN) (13) or the auriculotemporal nerve (14). In additional, once tumor has accessed a central location such as the gasserian ganglion or cavernous sinus, it may involve additional cranial nerves by spreading in an antegrade fashion, as was seen with patient 3 (Fig 1). It is important to recognize that, even though patients may not report symptoms of cranial nerve dysfunction, they may still demonstrate perineural spread of tumor on imaging (15).

Imaging-based techniques such as CT-guided fine needle aspiration (FNA) of abnormal soft tissue along or adjacent to cranial nerves may be useful for diagnosis of perineural spread (16). Of note, however, FNA of desmoplastic lesions often yields only scant material, and definitive diagnosis can be difficult. In our two cases where CT-FNA was attempted, the FNA was nondiagnostic and open biopsy was required. There has been a recent report of using FDGPET scans to follow patients with desmoplastic mel- 

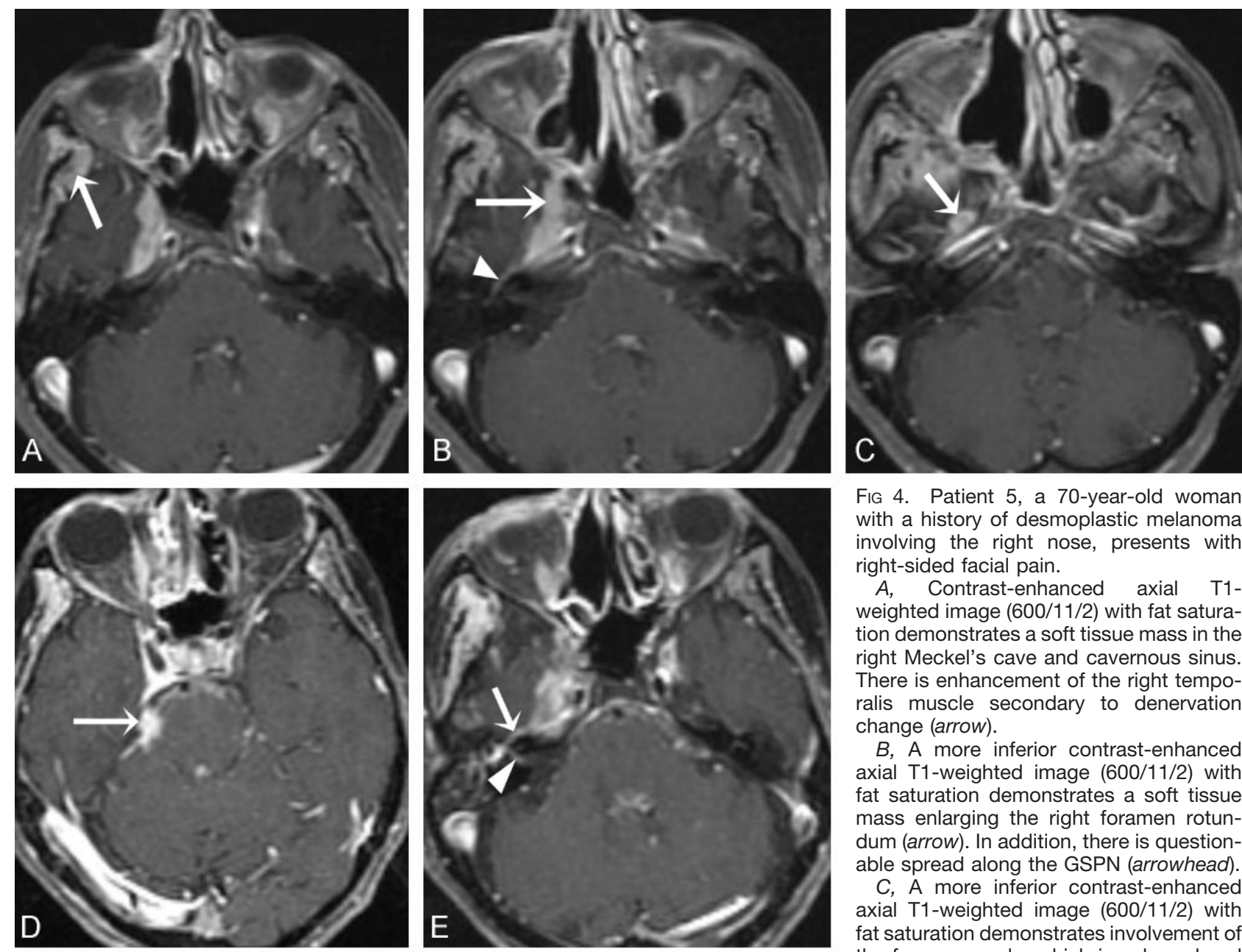

FIG 4. Patient 5, a 70-year-old woman with a history of desmoplastic melanoma involving the right nose, presents with right-sided facial pain.

$A$, Contrast-enhanced axial T1weighted image (600/11/2) with fat saturation demonstrates a soft tissue mass in the right Meckel's cave and cavernous sinus. There is enhancement of the right temporalis muscle secondary to denervation change (arrow).

$B$, A more inferior contrast-enhanced axial T1-weighted image (600/11/2) with fat saturation demonstrates a soft tissue mass enlarging the right foramen rotundum (arrow). In addition, there is questionable spread along the GSPN (arrowhead).

$C$, A more inferior contrast-enhanced axial T1-weighted image (600/11/2) with fat saturation demonstrates involvement of the foramen ovale, which is enlarged and shows abnormal enhancement (arrow). The patient received gamma knife radiosurgery to the right skull base and adjacent soft tissues and improved symptomatically. One year after treatment, however, the patient had interval progression of disease to involve CNs III-XII on the right, and a follow-up MR was performed.

$D$, Contrast-enhanced axial T1-weighted image (600/11/2) with fat saturation demonstrates an enhancing soft tissue mass (arrow) at the level of the root entry zone of right CN V.

$E$, A more inferior contrast-enhanced axial T1-weighted image (600/11/2) with fat saturation shows progression in the right cavernous sinus/Meckel's cave region, as well as clear-cut enhancement of the right GSPN (arrow), with enhancement now extending into the distal right internal auditory canal (arrowhead).

anoma after radiation therapy treatment (17) and FDG-PET may prove to be useful in the diagnosis, staging, and follow-up of these patients.

Desmoplastic melanoma is an uncommon variant of malignant melanoma that accounts for $5 \%$ of all cases. Most patients present in the 6th or 7th decade of life with an innocuous appearing nonpigmented dermal or subcutaneous nodule on the head and neck (18). Desmoplastic melanoma may also involve other anatomic sites, including the trunk (14\%), extremities $(14 \%)$, mucosa (2\%), and genitals $(0.6 \%)(19)$. Neurotropism with perineural invasion of nerve fascicles by tumor is a common feature of desmoplastic melanoma, and histologically the desmoplastic melanomas may closely resemble peripheral nerve sheath tumors because of the prominent schwannian and perineural features evident on light microscopy, immunohistochemistry, and electron microscopy (20).

In 1998, Quinn et al (21) published a series of 280 patients with desmoplastic melanoma. In this series,
90 patients had pathologic evidence of neurotropism, but only two patients developed cranial neuropathy. The actual incidence of desmoplastic melanoma progressing to clinical cranial neuropathy remains to be determined, but Quinn et al's experience would suggest that the numbers will be low, on the order of $1 \%-2 \%$. In contrast to other melanomas, desmoplastic melanoma exhibits a lower rate of lymph node involvement and distant metastases at initial presentation, but has an elevated risk (up to 20\%) for local recurrence (21) when perineural invasion has occurred. The overall 5-year survival rate of $75 \%$ (21) for patients with desmoplastic melanoma is reported to be equivalent to patients with other cutaneous melanomas.

Mucosal melanoma is a rare and highly malignant form of head and neck melanoma. In the National Cancer Data Base report of more than 84,000 melanomas seen from 1985 to 1994 (22), only 1.3\% were melanomas that arose from mucosal surfaces, of 
FIG 5. Patient 6, a 49-year-old woman presenting with a mass on her left upper lip. Biopsy confirmed melanoma, and she was treated with surgery and radiation. A follow-up scan was performed in April 2002, 5 months after her initial surgery, and further follow-up was performed in October 2002.

$A$, Coronal T1-weighted image $(600 /$ $11 / 2$ ) demonstrates no abnormality of the infraorbital nerve.

$B$, In follow-up 6 months later, the patient noted left cheek numbness and tingling, and a repeat MR was performed. Coronal T1-weighted image (600/11/2) was initially interpreted as negative, but further review demonstrates enlargement of the left infraorbital nerve (arrow).

C, Coronal T2-weighted image (4000/ 102/2) demonstrating that the enlarged left infraorbital nerve is low in signal intensity and not consistent with benign sinus contents adjacent to the infraorbital canal.

$D$, Contrast-enhanced coronal T1weighted image (600/11/2) with fat saturation demonstrating clear cut enlargement and enhancement of the left infraorbital nerve. The patient was taken to repeat resection, and perineural spread of malignant melanoma was confirmed.
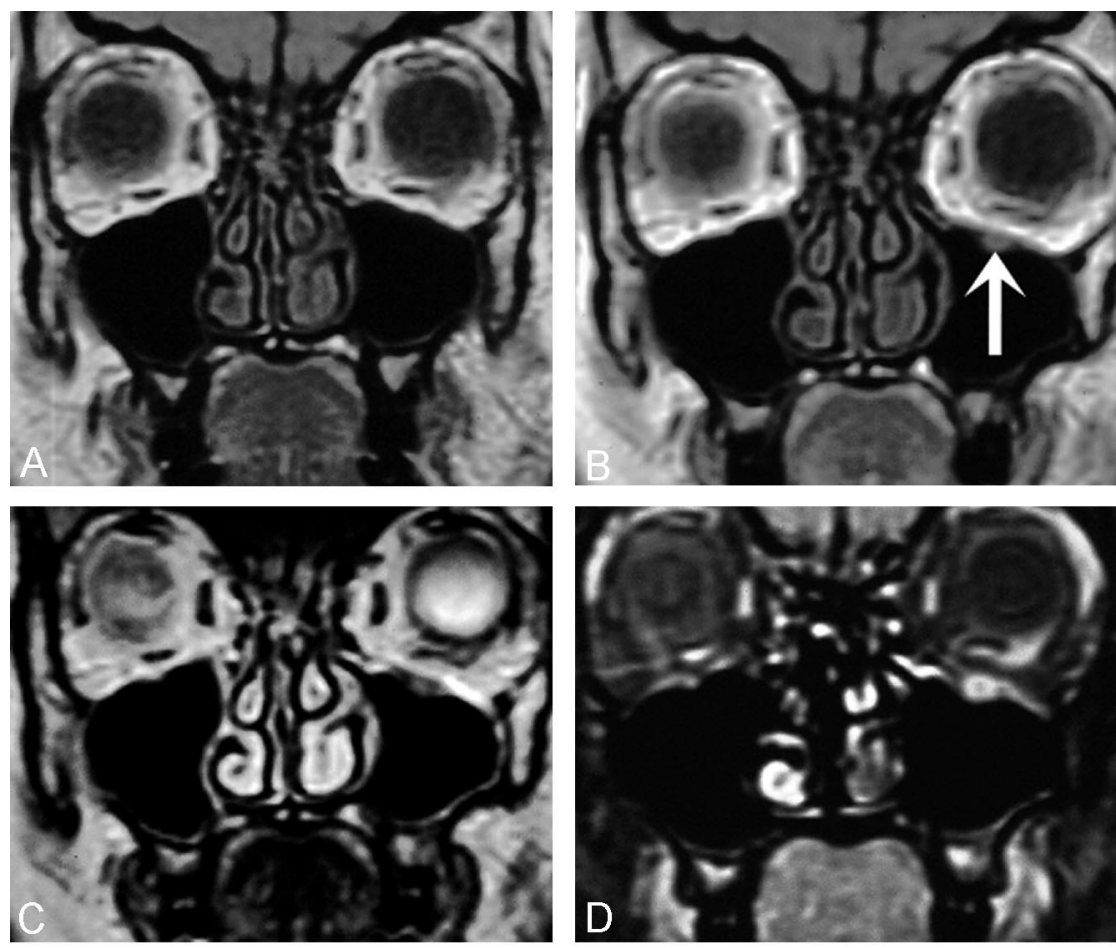

which 55\% were of the head and neck. The average 5 -year disease-specific survival was only $17.1 \%$ in a recent review of 21 reports (23). The presence of vascular invasion was the most important parameter relating to disease-specific survival. Cases of mucosal melanoma are usually marked by a course with multiple local recurrences of disease before distant metastases develop and death occurs (24). We did not identify any reports in the literature that clearly described cases of mucosal malignant melanoma exhibiting perineural spread along cranial nerves.

Management of patients with melanoma is primarily surgical, with wide local excision at the primary site and in some cases regional nodal sampling and/or dissection. If perineural spread of disease is discovered, external beam radiation therapy, gamma knife radiosurgery, and/or chemotherapy can be offered, if appropriate. For hematogenously disseminated metastatic disease, chemotherapy and immunotherapy are the mainstays of treatment. As with most forms of malignant melanoma, radiation therapy and chemotherapy have limited success rates, but cases of significant palliation and improved survival have been reported with aggressive local treatment $(17,25)$. In our patients treated with gamma knife, the growth of treated sites of disease was arrested for up to 1 year after treatment. Disease did then progress, however, and in patient 5 (Fig 4) gamma knife therapy ultimately failed.

Patients with biopsy-proved cases of melanoma of the head and neck will benefit from diligent evaluation of both the initial pathology samples and the MR imaging evaluations for perineural spread. Initial pathology samples from patient 1 on retrospective review demonstrated microscopic signs of perineural invasion that were missed on the initial assessment.
This patient had no symptomatic cranial neuropathy at the time and may have been curable with more aggressive resection ( $>1-\mathrm{cm}$ margins) and follow-up radiation therapy. In addition, patient 6 (Fig 5) developed cranial neuropathy and on MR imaging had signs of perineural spread of disease involving her left $\mathrm{CN}$ V2 that were not identified on an initial evaluation. Earlier recognition of perineural spread could possibly have helped this patient focus on more palliative therapies rather than aggressive treatments.

The differential diagnosis of perineural enhancement on MR imaging includes many infectious, neoplastic, and inflammatory processes. Invasive fungal infections such as Aspergillus and Mucormycosis may extend along cranial nerves to the skull base and may lead to nerve enlargement and enhancement, but usually affect only severely immune-compromised individuals (6). Primary neural tumors such as schwannomas typically present as discrete well-circumscribed masses, but can extend in a more diffuse and infiltrative fashion as well (26). Squamous cell carcinoma and lymphoma can involve single or multiple cranial nerves, as can adenoid cystic carcinoma. Meningeal carcinomatosis and other inflammatory meningeal conditions such as sarcoidosis, syphilis, or Lyme disease can also lead to enhancement of cranial nerves. Bilaterally symmetrical involvement of cranial nerves is a useful criterion to distinguish many of these nonneoplastic lesions from perineural spread of tumor, which is typically unilateral, but inflammatory processes may also be unilateral. Furthermore, lymphoma may involve cranial nerves in a bilateral and relatively symmetrical fashion, hampering its distinction from infectious or noninfectious inflammatory processes (5). 


\section{Conclusion}

Our retrospective analysis of eight patients, five of whom had desmoplastic histology, showed an average delay in onset of clinical neuropathy of 4.9 years after the time of presentation of the original lesion. Even after the appearance of cranial nerve symptoms, there was an average delay in definitive diagnosis of perineural spread of 7.1 months. Although perineural spread of disease is reported most commonly with squamous cell carcinoma and adenoid cystic carcinoma, we stress the importance of considering malignant melanoma in the differential diagnosis of perineural spread of head and neck tumor, particularly if the patient's pathology is known to be desmoplastic.

\section{Acknowledgments}

We appreciate the assistance provided by Dr. Barton F. Branstetter IV with regard to obtaining clinical follow-up on several of our patients.

\section{References}

1. Johnson TM, Smith JW 2nd, Nelson BR, Chang A. Current therapy for cutaneous melanoma. J Am Acad Dermatol 1995;32:689707

2. Jemal A, Thomas A, Murray T, Thun M. Cancer statistics, 2002. CA Cancer J Clin 2002;52:23-47

3. Elwood JM, Lee JA. Recent data on the epidemiology of malignant melanoma. Semin Oncol 1975;2:149-154

4. Balch CM, Karakousis C, Mettlin C, et al. Management of cutaneous melanoma in the United States. Surg Gynecol Obstet 1984;158: 311-318

5. Russo CP, Smoker WR, Weissman JL. MR appearance of trigeminal and hypoglossal motor denervation. AJNR Am J Neuroradiol 1997; $18: 1375-1383$

6. Parker GD, Harnsberger HR. Clinical-radiologic issues in perineural tumor spread of malignant diseases of the extracranial head and neck. Radiographics 1991;11:383-399

7. Catalano PJ, Sen C, Biller HF. Cranial neuropathy secondary to perineural spread of cutaneous malignancies. Am J Otol 1995;16: $772-777$

8. Majoie CB, Hulsmans FJ, Verbeeten B Jr, et al. Perineural tumor extension along the trigeminal nerve: magnetic resonance imaging findings. Eur J Radiol 1997;24:191-205
9. Terashi H, Kurata S, Tadokoro T, et al. Perineural and neural involvement in skin cancers. Dermatol Surg 1997;23:259-264; discussion 264-255

10. Caldemeyer KS, Mathews VP, Righi PD, Smith RR. Imaging features and clinical significance of perineural spread or extension of head and neck tumors. Radiographics 1998;18:97-110; quiz 147

11. Batsakis JG. Nerves and neurotropic carcinomas. Ann Otol Rhinol Laryngol 1985;94:426-427

12. Perniciaro C. Dermatopathologic variants of malignant melanoma. Mayo Clin Proc 1997;72:273-279

13. Ginsberg LE, De Monte F, Gillenwater AM. Greater superficial petrosal nerve: anatomy and MR findings in perineural tumor spread. AJNR Am J Neuroradiol 1996;17:389-393

14. Schmalfuss IM, Tart RP, Mukherji S, Mancuso AA. Perineural tumor spread along the auriculotemporal nerve. $A J N R A m J N e u$ roradiol 2002;23:303-311

15. Su CY, Lui CC. Perineural invasion of the trigeminal nerve in patients with nasopharyngeal carcinoma. Imaging and clinical correlations. Cancer 1996;78:2063-2069

16. Barakos JA, Dillon WP. Lesions of the foramen ovale: CT-guided fine-needle aspiration. Radiology 1992;182:573-575

17. Hannah A, Feigen M, Quong G, et al. Use of [F]-fluorodeoxyglucose positron emission tomography in monitoring response of recurrent neurotropic desmoplastic melanoma to radiotherapy. Otolaryngol Head Neck Surg 2000;122:304-306

18. Jain S, Allen PW. Desmoplastic malignant melanoma and its variants: a study of 45 cases. Am J Surg Pathol 1989;13:358-373

19. Carlson JA, Egbert BM. Desmoplastic neurotropic malignant melanoma. Pathology (Phila) 1994;2:339-357

20. Carlson JA, Dickersin GR, Sober AJ, Barnhill RL. Desmoplastic neurotropic melanoma: a clinicopathologic analysis of 28 cases. Cancer 1995;75:478-494

21. Quinn MJ, Crotty KA, Thompson JF, et al. Desmoplastic and desmoplastic neurotropic melanoma: experience with 280 patients. Cancer 1998;83:1128-1135

22. Chang AE, Karnell LH, Menck HR. The National Cancer Data Base report on cutaneous and noncutaneous melanoma: a summary of 84,836 cases from the past decade. The American College of Surgeons Commission on Cancer and the American Cancer Society. Cancer 1998;83:1664-1678

23. Manolidis S, Donald PJ. Malignant mucosal melanoma of the head and neck: review of the literature and report of 14 patients. Cancer 1997;80:1373-1386

24. Patel SG, Prasad ML, Escrig M, et al. Primary mucosal malignant melanoma of the head and neck. Head Neck 2002;24:247-257

25. Anderson TD, Weber RS, Guerry D, et al. Desmoplastic neurotropic melanoma of the head and neck: the role of radiation therapy. Head Neck 2002;24:1068-1071

26. Sangueza OP, Requena L. Neoplasms with neural differentiation: a review. Part II. Malignant neoplasms. Am J Dermatopathol 1998; 20:89-102 